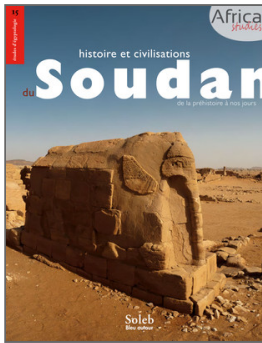

Histoire et civilisation du Soudan

De la préhistoire à nos jours

\title{
Les réfugiés
}

\section{Odile Nicoloso}

DOI : 10.4000/books.africae. 2967

Éditeur : Africae, Soleb, Bleu autour

Lieu d'édition : Paris, Khartoum

Année d'édition : 2017

Date de mise en ligne : 17 janvier 2022

Collection : Africae Studies

EAN électronique : 9782493207074

\section{Q OpenEdition \\ Books}

http://books.openedition.org

\section{Référence électronique}

NICOLOSO, Odile. Les réfugiés In : Histoire et civilisation du Soudan : De la préhistoire à nos jours [en ligne]. Paris, Khartoum : Africae, 2017 (généré le 28 janvier 2022). Disponible sur Internet : <http:// books.openedition.org/africae/2967>. ISBN : 9782493207074. DOI : https://doi.org/10.4000/ books. africae. 2967. 


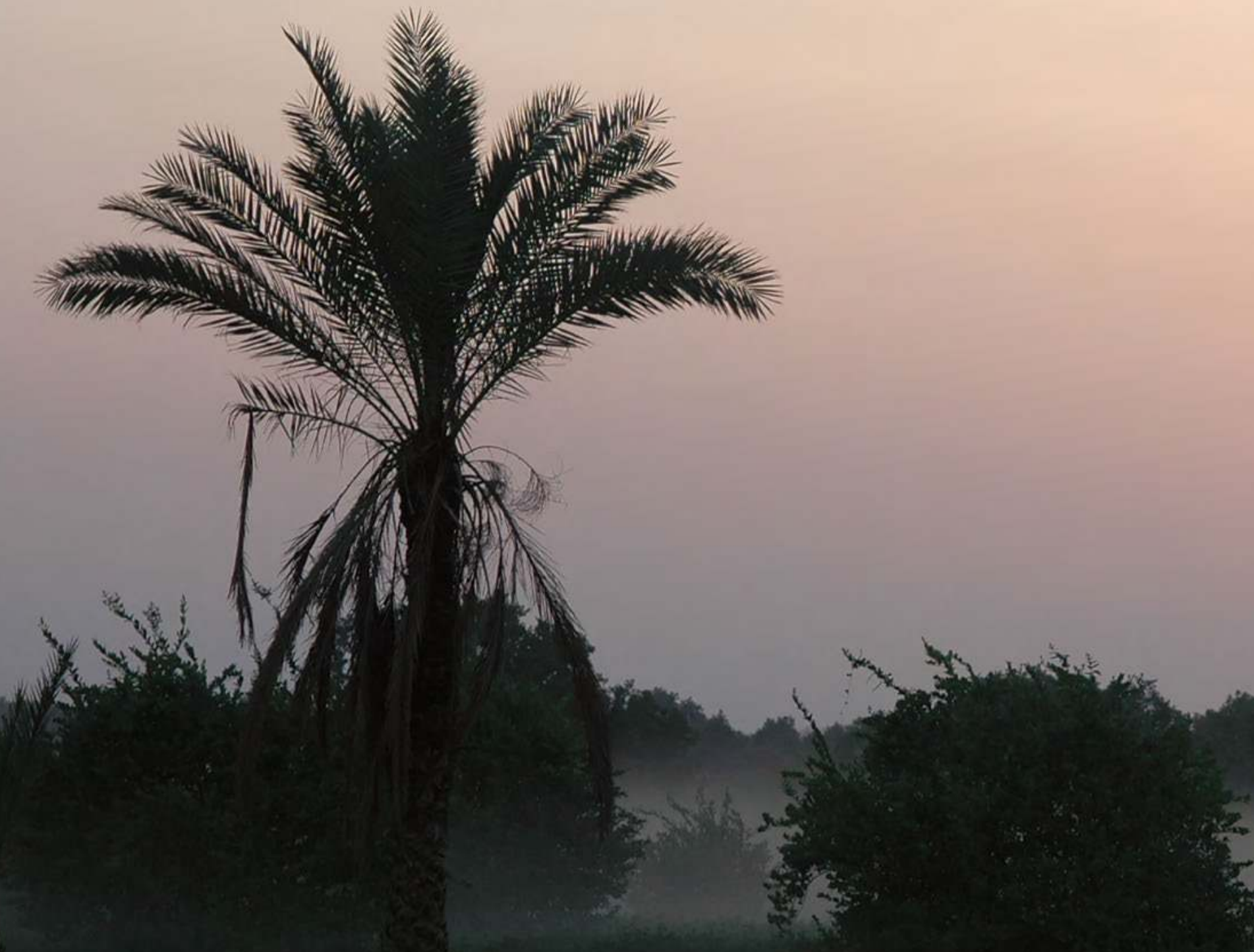




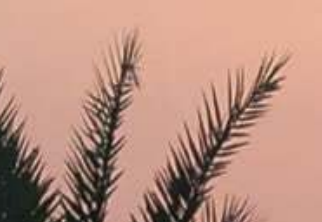

\title{
les réfugiés
}

\author{
-dile Nicoloso
}


Le Soudan est une terre d'accueil pour les nombreux réfugiés politiques ou économiques des pays voisins, tels que l'Érythrée, la Somalie et l'Éthiopie. Ces réfugiés s'ajoutent aux " déplacés internes » (les centaines de milliers de civils fuyant la guerre au Sud Soudan ou au Darfour) et aux nombreux pèlerins qui, de retour de la Mecque, autrefois, se sont fixés ici et y ont fait souche pour former la population des Fellata.

\section{Témoignage de Genet, Érythréenne}

le Soudan

828

aujourd'hui
Genet, est triste: elle doit rendre visite aux familles de jeunes qui sont morts la semaine passée, à la suite du naufrage d'un bateau clandestin en Méditerranée. Tous très jeunes, ils avaient leur famille dans le quartier d'al-Sahafa, à Khartoum, peuplé majoritairement d'Éthiopiens et d'Érythréens.

En avril 2011, plus de 300 Érythréens sont morts en Méditerranée, à $20 \mathrm{~km}$ à peine de la côte libyenne. Ils rêvaient tous d'un avenir meilleur, loin de leur pays asphyxié par un régime à la dérive.

Par le passé, Khartoum a accueilli les Érythréens fuyant la guerre sanglante qui les opposait à l'Éthiopie et se termina par la création de leur propre pays en 1993. Depuis peu, le nombre de jeunes Érythréens présents ici a sensiblement augmenté: ils fuient le service militaire et les conditions de vie dans leur patrie.

Il y a trente ans, pendant cette guerre, Genet a fui l'Érythrée à pied. Actuellement, elle vit à Khartoum et, avec environ 150 euros par mois, entretient cinq enfants et une mère qui vit à Asmara. Elle fait le ménage chez des expatriés et, une fois son travail terminé, s'occupe de sa famille qu'elle réunit autour de la traditionnelle cérémonie du café.

Il y a quelques années, sa fille a décidé de migrer en camion jusqu'au Royaume-Uni. Aujourd'hui elle vit à Manchester et, hasard du destin, travaille comme femme de ménage chez des Soudanais. Genet ne l'a pas vue depuis cinq ans: elles communiquent parfois depuis un cybercafé et sa fille lui dit qu'il fait très froid là-bas! L'apparition en Afrique du téléphone mobile et d'internet a révolutionné les contacts entre les familles restées dans des villages lointains et leurs enfants vivant dans les grandes métropoles occidentales.

Genet veut croire en une vie meilleure pour sa fille et ses petitsenfants en Europe, où certains de ses proches ont déjà immigré. Sa foi chrétienne lui permet de croire que ses sacrifices seront récompensés.

Les Érythréens sont souvent la proie de mafias au Soudan, en Égypte ou au Moyen Orient. Ils subissent violences et mauvais traitements et sont même parfois assassinés par des policiers corrompus... Certains 
échouent dans les quartiers défavorisés de Tel Aviv, dans les prisons de Beyrouth ou deviennent esclaves domestiques dans des familles libanaises aussi bien chrétiennes que musulmanes.

Genet s'habille du tob soudanais pour paraître décente selon les critères de Khartoum et se faire passer pour une Soudanaise, car les Érythréennes ont la réputation de femmes «faciles». Aujourd'hui, dans le quartier d'al-Sahafa, à Khartoum, elle ira, vêtue de blanc, rendre un dernier hommage aux jeunes qui sont morts dans les eaux méditerranéennes, tandis que la jeunesse continuera de rêver à un meilleur avenir en Occident.

\section{0 réfugiés Syriens}

Depuis 2011, environ 200000 Syriens sont arrivés à Khartoum, ce qui fait du Soudan le cinquième pays d'accueil après la Turquie, le Liban, la Jordanie, l'Irak et l'Égypte. Un traitement particulièrement bienveillant leur est réservé de la part des autorités soudanaises qui n'appliquent pas de visa d'entrée à leur égard. De ce fait, leur arrivée a connu une nette accélération en 2015. Ce sont pour la plupart des hommes d'une trentaine d'années qui sont musulmans sunnites et originaires de milieux urbains. Ils arrivent souvent via les vols hebdomadaires qui relient Damas et Khartoum. Nombreux sont ceux qui viennent pour échapper au service militaire, en profitant de la sécurité qui règne à Khartoum et en attendant la fin de la guerre dans leur pays. Seulement $30 \%$ des Syriens considèrent le Soudan comme un lieu de transit vers l'Europe; mais certains envisagent de s'y rendre pour y étudier — particulièrement en Suède - et, dans ce cas, le font majoritairement par la voie légale.

Au Soudan, les Syriens ne sont pas considérés comme des réfugiés: ils peuvent y résider aussi longtemps qu'ils le souhaitent, obtenir un permis de travail et acquérir la nationalité soudanaise sans perdre la leur. Le gouvernement apporte également son soutien aux plus démunis et aux Ong syriennes d'aide aux familles. Du point de vue économique, les Syriens qui arrivent au Soudan sont considérés comme des atouts: beaucoup sont autonomes sur le plan financier; ils ouvrent de nombreux commerces et restaurants ou occupent des postes qualifiés -

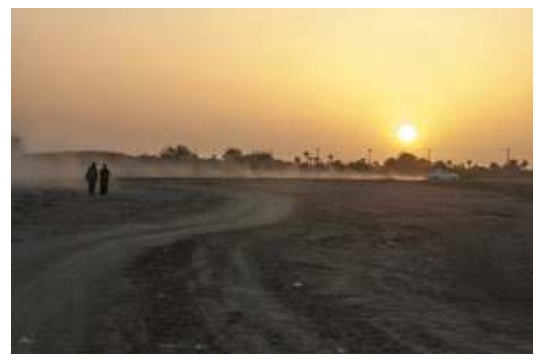

